This item was submitted to Loughborough's Research Repository by the author.

Items in Figshare are protected by copyright, with all rights reserved, unless otherwise indicated.

\title{
The effect of surface preparation on the precipitation of sigma during high temperature exposure of S32205 duplex stainless steel
}

\section{PLEASE CITE THE PUBLISHED VERSION}

http://dx.doi.org/10.1007/s11661-016-3914-8

\section{PUBLISHER}

(C) The Authors. Published by Springer Verlag (Germany)

\section{VERSION}

VoR (Version of Record)

\section{PUBLISHER STATEMENT}

This work is made available according to the conditions of the Creative Commons Attribution 4.0 International (CC BY 4.0) licence. Full details of this licence are available at: http://creativecommons.org/licenses/ by/4.0/

\section{LICENCE}

CC BY 4.0

\section{REPOSITORY RECORD}

Jepson, Mark, Rebecca Higginson, and Matthew Rowlett. 2017. "The Effect of Surface Preparation on the Precipitation of Sigma During High Temperature Exposure of S32205 Duplex Stainless Steel”. figshare. https://hdl.handle.net/2134/23562. 


\title{
The Effect of Surface Preparation on the Precipitation of Sigma During High Temperature Exposure of S32205 Duplex Stainless Steel
}

\begin{abstract}
MARK A.E. JEPSON, MATTHEW ROWLETT, and REBECCA L. HIGGINSON
Although the formation of sigma phase in duplex stainless steels is reasonably well documented, the effect of surface finish on its formation rate in surface regions has not been previously noted. The growth of the sigma phase precipitated in the subsurface region (to a maximum depth of $120 \mu \mathrm{m}$ ) has been quantified after heat treatment of S32205 duplex stainless steel at $1073 \mathrm{~K}$ $\left(800{ }^{\circ} \mathrm{C}\right)$ and $1173 \mathrm{~K}\left(900^{\circ} \mathrm{C}\right)$ after preparation to two surface finishes. Here, results are presented that show that there is a change in the rate of sigma phase formation in the surface region of the material, with a coarser surface finish leading to a greater depth of precipitation at a given time and temperature of heat treatment. The growth rate and morphology of the precipitated sigma has been examined and explored in conjunction with thermodynamic equilibrium phase calculations.
\end{abstract}

DOI: $10.1007 / \mathrm{s} 11661-016-3914-8$

(C) The Author(s) 2016. This article is published with open access at Springerlink.com

\section{INTRODUCTION}

DUPLEX stainless steels have received considerable attention in the recent years due their good corrosion resistance and mechanical properties while maintaining a competitive price ${ }^{[1]}$ Duplex stainless steels are a group of stainless steel alloys where the alloying additions are such that the microstructure is made up of austenite (fcc) and ferrite (bcc). This mixture of phases, usually with a 50/50 distribution, gives this alloy group good corrosion resistance as well as strength when compared to either austenitic or ferritic grades. ${ }^{[1,2]}$ They are extensively utilized in advanced applications where their corrosion resistance and strength make them ideal in aggressive environments, for example, in the gas and oil and chemical industries. Although these alloys are generally used at ambient temperatures, they may be subjected to high temperatures during processing and/or fabrication (e.g., welding). As well as causing the formation of oxide scales, these high temperatures may influence the distribution of phases within the metal such as austenite, ferrite, Chi, and sigma phase, which is known to form even at relatively modest temperatures in these alloys. ${ }^{[2,3,4]}$

Sigma phase is an intermetallic phase containing $\sim 30$ pet $\mathrm{Cr}, 4$ pet Ni, and 7 pet Mo. ${ }^{[5]}$ Its formation is usually in the ferrite grains with reports showing that it predominantly forms on the fcc/bcc phase boundaries and bcc triple points. ${ }^{[6,1]}$ After as little as 10 hours at 973 $\mathrm{K}\left(700{ }^{\circ} \mathrm{C}\right),{ }^{[4]} 100 \mathrm{pct}$ of the ferrite can transform to

MARK A.E. JEPSON, MATTHEW ROWLETT, and REBECCA L. HIGGINSON are with the Department of Materials, Loughborough University, Loughborough, Leicestershire LE11 3TU, U.K. Contact e-mail: m.a.e.jepson@lboro.ac.uk

Manuscript submitted June 10, 2016. sigma phase, although its morphology can vary depending on temperature and prior microstructure. This phase is of particular importance as it can have a deleterious effect on the mechanical properties of the steel, for example, its impact properties. ${ }^{7,8]}$

The two phases in duplex stainless steel not only have different crystal structures, but also vary in chemistry with the austenite and ferrite stabilizing elements favoring one or other phase. This difference may only be less than $1 \mathrm{wt}$ pet but can lead to differences in the corrosion and high temperature oxidation characteristics of the two phases. ${ }^{[9,10]}$

Although the formation of sigma in the bulk is relatively well documented (e.g., References 3,6,8,11), there appears to be no information on its formation in the surface regions of the alloy. Observations presented here demonstrate the importance of surfaces and surface finish on the initial formation of sigma phase, which may have wider reaching consequences for the assessment of the second phase formation of these alloys and the need for surface preparation control during processing.

\section{EXPERIMENTAL PROCEDURE}

The initial material was an as-cast block of S32205 duplex stainless steel, with the nominal composition shown in Table I.

For heating experiments, smaller samples were produced measuring $10 \times 5 \times 5 \mathrm{~mm}$ using a precision cutting saw at a low cutting speed to ensure that surface heating and damage was minimized. Prior to heating, the surfaces of the samples were prepared to two different surface finishes such that, when mounted, the cross sections of both prepared faces could be observed and identified (Figure 1). The faces were ground using 
Table I. Nominal Chemical Composition of 2205 Duplex Stainless Steel, Wt Pct

\begin{tabular}{cccccccc}
\hline & $\mathrm{C}$ & $\mathrm{N}$ & $\mathrm{Cr}$ & $\mathrm{Ni}$ & $\mathrm{Mo}$ & $\mathrm{Si}$ & $\mathrm{Mn}$ \\
\hline $\mathrm{S} 32205$ & 0.02 & 0.17 & 22.00 & 5.70 & 3.10 & 0.4 & 1.50 \\
\hline
\end{tabular}

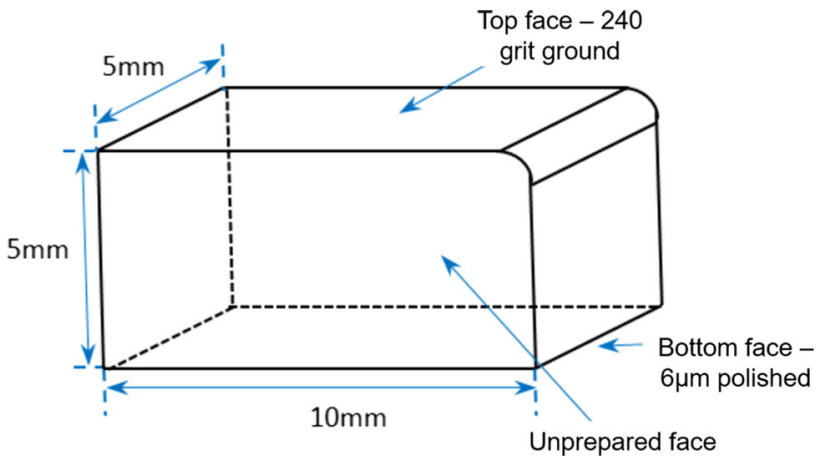

Fig. 1-Schematic of the sample preparation prior to heat treatment.

successively finer grades of $\mathrm{SiC}$ paper (with water as a lubricant) to a finish of either 240 grit or finished with a polishing stage using a $6 \mu \mathrm{m}$ diamond suspension. This operation was carried out manually to ensure that grinding damage was unidirectional.

Heat treatments of the prepared specimens were carried out in a box furnace in laboratory air at temperatures of $1073 \mathrm{~K}\left(800{ }^{\circ} \mathrm{C}\right), 1173 \mathrm{~K}\left(900{ }^{\circ} \mathrm{C}\right)$, or $1273 \mathrm{~K}\left(1000{ }^{\circ} \mathrm{C}\right)$ for times varying from 5 to 480 minutes. Once the time for the heat treatment had been reached, samples were removed from the furnace and left to cool in air. As the sample size was small, this can be considered a rapid cooling air-quench.

After heat treatment, samples were mounted in electrically conductive Bakelite such that the prepared surfaces were in cross section, with a maximum mounting press operating temperature of $473 \mathrm{~K}\left(200{ }^{\circ} \mathrm{C}\right)$ and for a mounting time of 6 minutes. The mounted samples were then ground using successively finer grades of $\mathrm{SiC}$ paper to a finish of 1200 grit followed by polishing using $6 \mu \mathrm{m}$ and then $1 \mu \mathrm{m}$ diamond suspensions with an additional stage of 20-minute chemo/mechanical polishing using a $0.05 \mu \mathrm{m}$ colloidal silica solution (Buehler, U.K.). Etching of the thermally exposed samples was carried out using Shaftmeisters reagent $(50 \mathrm{~mL}$ HCL, 5 $\mathrm{mL} \mathrm{HNO}_{3}, 50 \mathrm{~mL} \mathrm{H} \mathrm{H}_{2} \mathrm{O}$ ) by immersion for approximately 30 seconds to reveal the duplex microstructure and the location of secondary phase precipitates. The as-received sample was polished as described above and electrolytically etched using 10 pct potassium hydroxide in water at a voltage of $5 \mathrm{~V}$ for approximately 5 to 10 seconds etching time.

For the area percentage determination, ImageJ software was used to threshold the sigma from the ferrite and austenite matrix material and an area fraction determined. Measurements were taken at different depths from the prepared surface within the sample, 0 to 40,40 to 80 , and 80 to $120 \mu \mathrm{m}$, across the whole surface length of the mounted cross section.

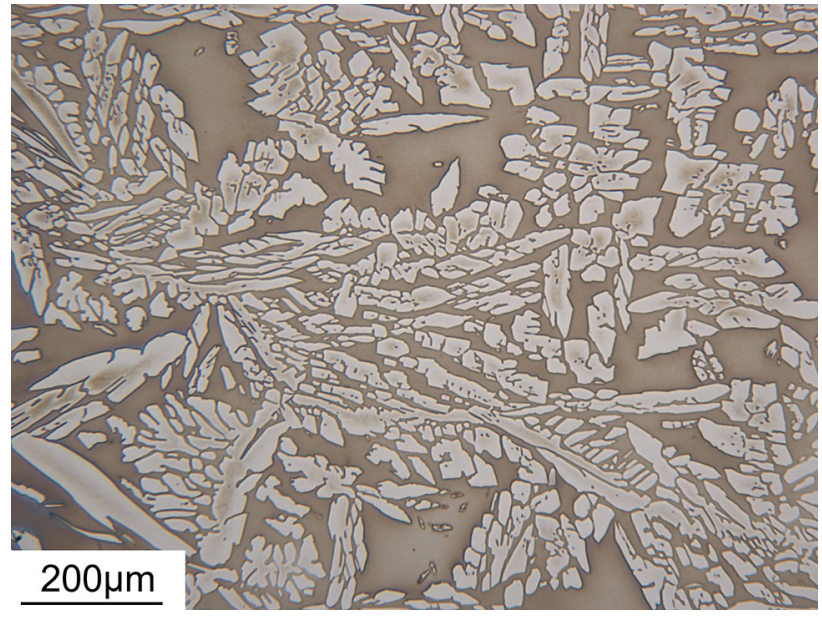

Fig. 2-Optical micrograph of the as-received and etched material.

X-ray diffraction (XRD) was carried out using a Bruker D8 XRD machine using Ni-filtered $\mathrm{Cu} \mathrm{K}_{\alpha}$ radiation with an accelerating voltage of $30 \mathrm{kV}$ and a current of $10 \mathrm{~mA}$. Two-theta $(2 \theta)$ data were collected between $30 \mathrm{deg}$ and $95 \mathrm{deg}$ at a step size of $0.01 \mathrm{deg}$ for a count time of 1 second per step. Scanning electron microscopy (SEM) was carried out using a backscattered electron detector in a Leo 1530VP Field Emission Gun SEM (FEGSEM) with an accelerating voltage of $20 \mathrm{kV}$ and a working distance of 7 to $10 \mathrm{~mm}$ chosen to optimize contrast within the images. Energy-dispersive $\mathrm{X}$-ray spectroscopy (EDS) mapping was conducted in the same instrument with an Oxford Instruments X-Max EDS detector and Aztec software.

\section{RESULTS}

Figure 2 shows the as-received microstructure of the material. The structure consists of a ferrite, $\alpha$ (bcc) matrix, which appears as the darker phase in Figure 2, with islands of austenite, $\gamma$ (fcc), the brighter phase. As the material is in the as-cast condition, the austenite islands are randomly orientated across the area of the samples. Although the average structure is approximately $50 / 50$ ferrite/austenite, the distribution of austenite is not completely homogeneous, instead having areas which are locally higher in either phases.

Figure 3 shows backscattered electron (BSE) micrographs of the surface region of samples heat treated at $1073 \mathrm{~K}\left(800^{\circ} \mathrm{C}\right)$ for 60 and 120 minutes with a ground (Figures 3(a) and (b)) and polished (Figures 3(c) and (d)) initial surface finish. In this condition (i.e., after etching), the contrast between the ferrite and austenite phases is not consistent, but the process of etching 
shows an enhanced rate of attack for the ferrite compared to the austenite. At the surface, there is clear precipitation of a third phase which appears brighter in the images. These precipitates exist only in the ferrite grains and do not extend into the austenite grains with their growth apparently arrested at the ferrite/austenite phase boundaries. As the time at temperature increases, the depth of penetration is increased for both the polished and the ground surface finishes. From this limited overview, it is apparent that the depth of the secondary phase precipitation at the polished surface is reduced compared to the ground surface at the same thermal conditions.

Figure 4 shows BSE micrographs of the samples heat treated at $1173 \mathrm{~K}\left(900{ }^{\circ} \mathrm{C}\right)$ for 60 and 120 minutes. As with the $1073 \mathrm{~K}\left(800{ }^{\circ} \mathrm{C}\right)$ samples shown in Figure 3, there are clear differences in the precipitation and apparent growth rate of the precipitated phase, depending on the initial surface finish, with the ground surface showing both a greater area fraction of precipitate and a greater penetration into the ferrite phase regions, after both 60 and 120 minutes of exposure. The precipitates in the samples heat treated at $1173 \mathrm{~K}\left(900{ }^{\circ} \mathrm{C}\right)$ also have a different morphology, with a more angular (or blocky) morphology rather than coral-like or cellular morphology seen at $1073 \mathrm{~K}\left(800^{\circ} \mathrm{C}\right)$. In addition to the differences in precipitate morphology present after heating to $1173 \mathrm{~K}\left(900{ }^{\circ} \mathrm{C}\right)$, there also exists some fine austenite grains within the ferrite regions which were not present after heat treatment at $1073 \mathrm{~K}\left(800{ }^{\circ} \mathrm{C}\right)$. This is particularly evident in the polished samples as indicated by the circles in Figures 4(c) and (d). No precipitated phase was observed after heating to $1273 \mathrm{~K}\left(1000^{\circ} \mathrm{C}\right)$ at any of the times studied.

To clarify the nature of the phases present at the surface, X-ray diffraction (XRD) was carried out on the as-received material and a sample heat treated at $1173 \mathrm{~K}$ $\left(900{ }^{\circ} \mathrm{C}\right)$ for 240 minutes and subsequently cooled to room temperature before analysis. Prior to XRD, the oxide layer was carefully removed from the surface of the material using $\mathrm{SiC}$ paper taking care to cease grinding once some underlying metal was revealed. The results for the $30 \mathrm{deg}$ to $94 \mathrm{deg} 2 \theta$ are shown in Figure 5.

In order to assist with comparison, the data from the scan of the heat-treated sample has been offset by approximately 20,000 counts. In the as-received material, the two-phase structure of ferrite and austenite are clearly seen with strong peaks for the $\mathrm{fcc}_{(111)}$ and bcc $_{(100)}$ phases showing the highest peaks at $\sim 43.5 \mathrm{deg}$ and $44.5 \mathrm{deg}$, respectively. In the samples heat treated at $1173 \mathrm{~K}\left(900^{\circ} \mathrm{C}\right)$ for 240 minutes, there are some minor peaks also clearly visible in the trace. An extract of the region between $35 \mathrm{deg}$ and $55 \mathrm{deg}$ is shown in Figure 6

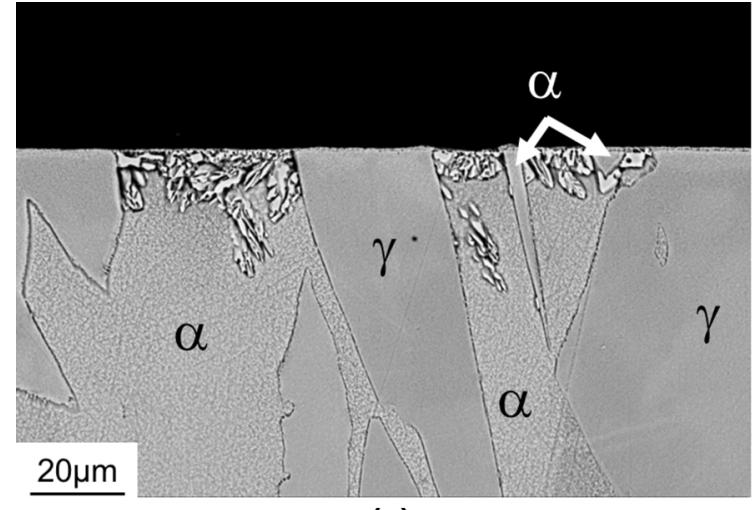

(a)

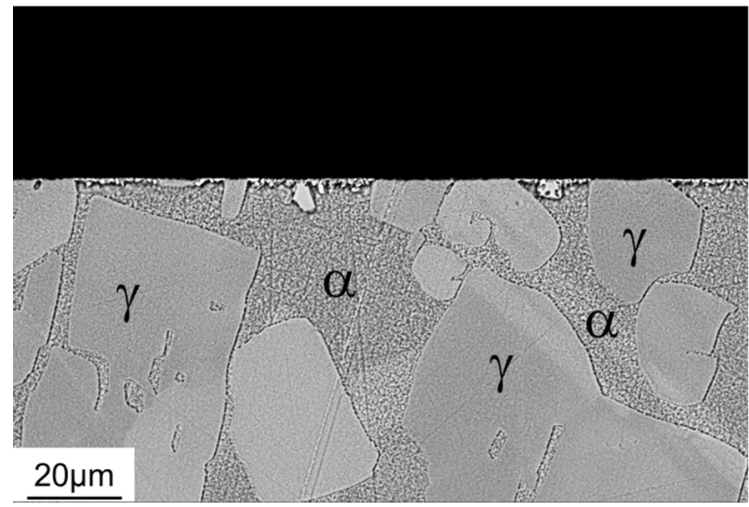

(c)

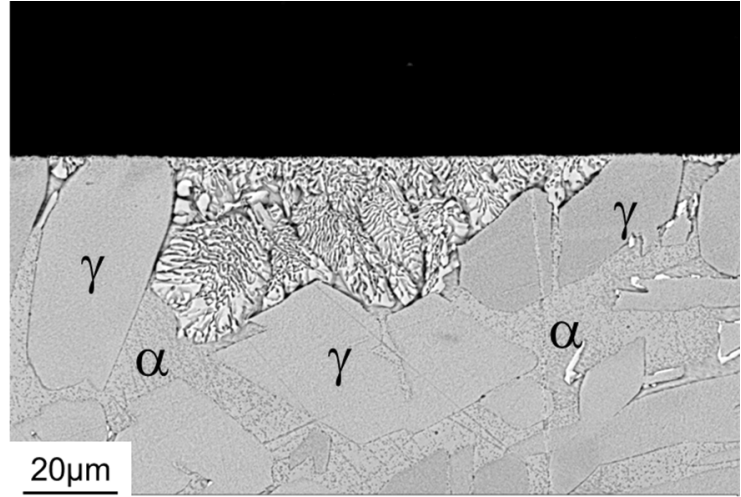

(b)

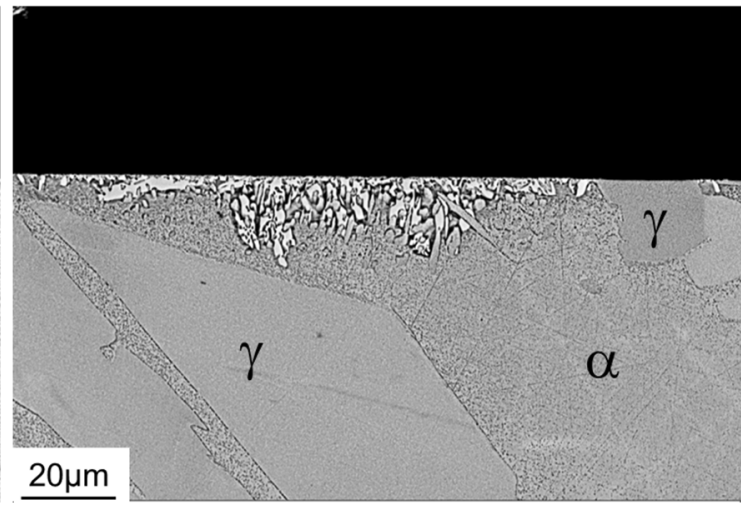

(d)

Fig. 3- Scanning electron micrographs of samples with a polished surface heat treated $(a)$ and $(b)$ at $1073 \mathrm{~K}\left(800{ }^{\circ} \mathrm{C}\right)$ and $(c)$ and $(d)$ at $1173 \mathrm{~K}$ $\left(900{ }^{\circ} \mathrm{C}\right)$ for $(a)$ and $(c) 60 \mathrm{~min}$ and $(b)$ and $(d) 120 \mathrm{~min}$. 


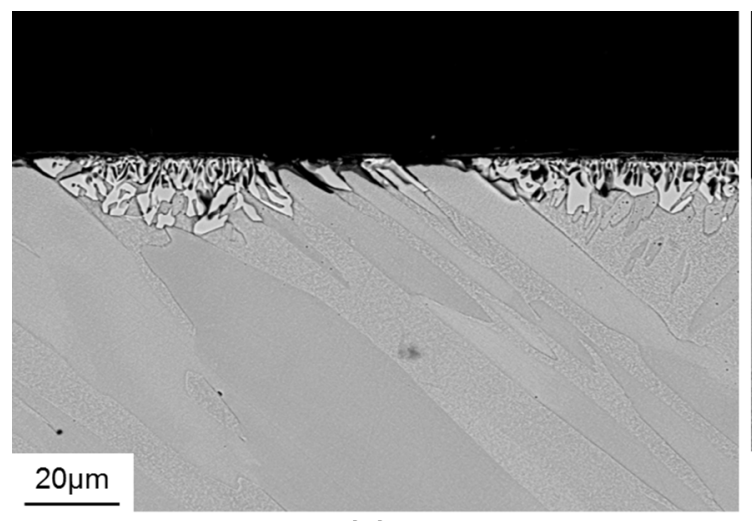

(a)

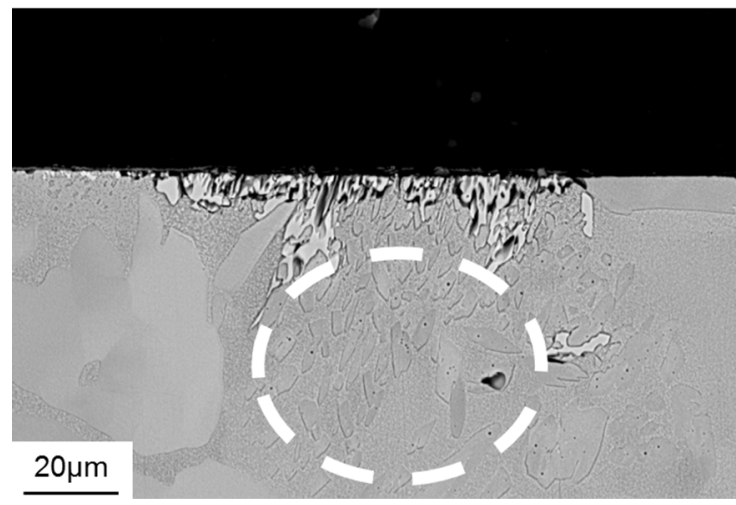

(c)

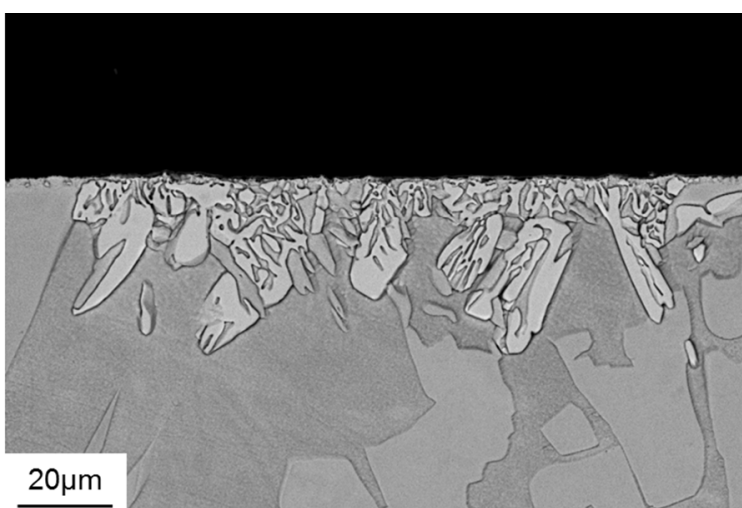

(b)

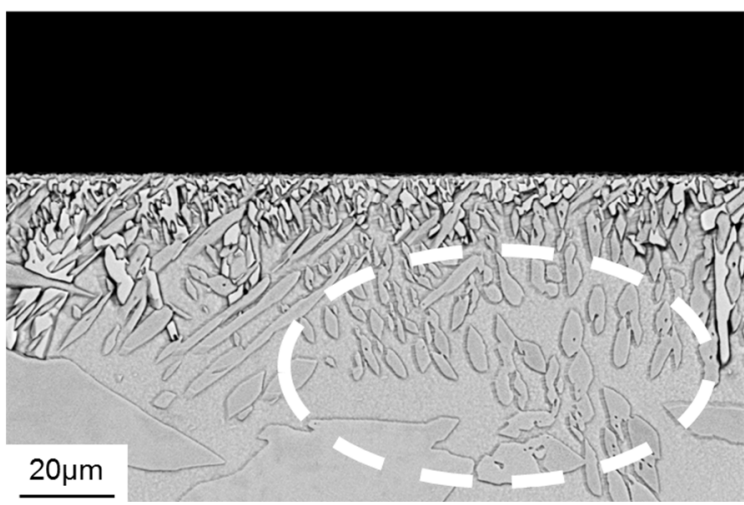

(d)

Fig. 4- Scanning electron micrographs of samples with a ground surface heat treated $(a)$ and $(b)$ at $1073 \mathrm{~K}\left(800{ }^{\circ} \mathrm{C}\right)$ and $(c)$ and $(d)$ at $1173 \mathrm{~K}$ $\left(900{ }^{\circ} \mathrm{C}\right)$ for $(a)$ and $(c) 60 \mathrm{~min}$ and $(b)$ and $(d) 120 \mathrm{~min}$.

with the expected positions of peaks from sigma $(\sigma)$ phase shown on the plot. There is some overlap between the $\mathrm{fcc}_{(111)}$ and the $\sigma_{(330)}$ peaks and the $\mathrm{bcc}_{(100)}$ and $\sigma_{(202)}$ peaks, but the other sigma peaks are clearly visible and are in agreement with other similar identification peaks for sigma. ${ }^{[12,13]}$

Figures 7 and 8 show EDS maps of the surface cross sections of the ground samples heat treated for 120 minutes at $1073 \mathrm{~K}\left(800^{\circ} \mathrm{C}\right)$ and $1173 \mathrm{~K}\left(900^{\circ} \mathrm{C}\right)$, respectively. In these maps, a greater concentration of an element is indicated by a higher number of white pixels. Therefore, a brighter region indicates higher concentrations of the stated element. As expected, in both samples, the ferrite and austenite regions show clear chemical differences with the ferrite stabilizing element, chromium, higher in the ferrite and nickel higher in the austenite. Figure 7 shows the chemistry of the region shown in Figure 3(b). Here, the sigma phase at the surface is enriched in molybdenum with a similar chromium and nickel content to the substrate and depletion in iron relative to the substrate. Figure 8 shows the samples heat treated at the higher temperature. The sigma phase is again enriched in molybdenum but, as mentioned previously, there is a clear difference in the morphology of the sigma phase and the surrounding microstructure with sigma appearing blockier at $1173 \mathrm{~K}\left(900{ }^{\circ} \mathrm{C}\right)$ than at $1073 \mathrm{~K}\left(800{ }^{\circ} \mathrm{C}\right)$. In between the sigma regions, there are small austenite grains that have formed. These grains are higher in nickel than the surrounding grain as well as higher in iron and lower in chromium, the same as the larger austenite islands in the as-received structure.

Figure 9 shows the quantification of area fraction of the sigma phase from the three bands of depth within the samples for both $1073 \mathrm{~K}\left(800{ }^{\circ} \mathrm{C}\right)$ and $1173 \mathrm{~K}$ $\left(900{ }^{\circ} \mathrm{C}\right)$ up to times of 480 minutes. This measurement of bands of depth was used due to the nature of the sigma phase forming primarily within the ferrite grains which, because of the large grain size, can give localized variation in the ferrite fraction at the surface of the sample. The ground and polished surface finishes are plotted together for comparison with the ground surface data plotted with the solid shapes and the polished with the outline shapes. Figure 9(a) shows the sigma phase quantification at $1073 \mathrm{~K}\left(800^{\circ} \mathrm{C}\right)$ where it can be seen that as the time at temperature increases, there is an increase in the amount of sigma formation at the surface. This increase is considerably faster on the ground surface than on the polished. At the maximum time studied of 480 minutes, the ground surface has an area percentage of $10.6 \mathrm{pct}$ sigma phase within the $1 \mathrm{st} 40$ $\mu \mathrm{m}$ from the prepared surface, and the polished sample 


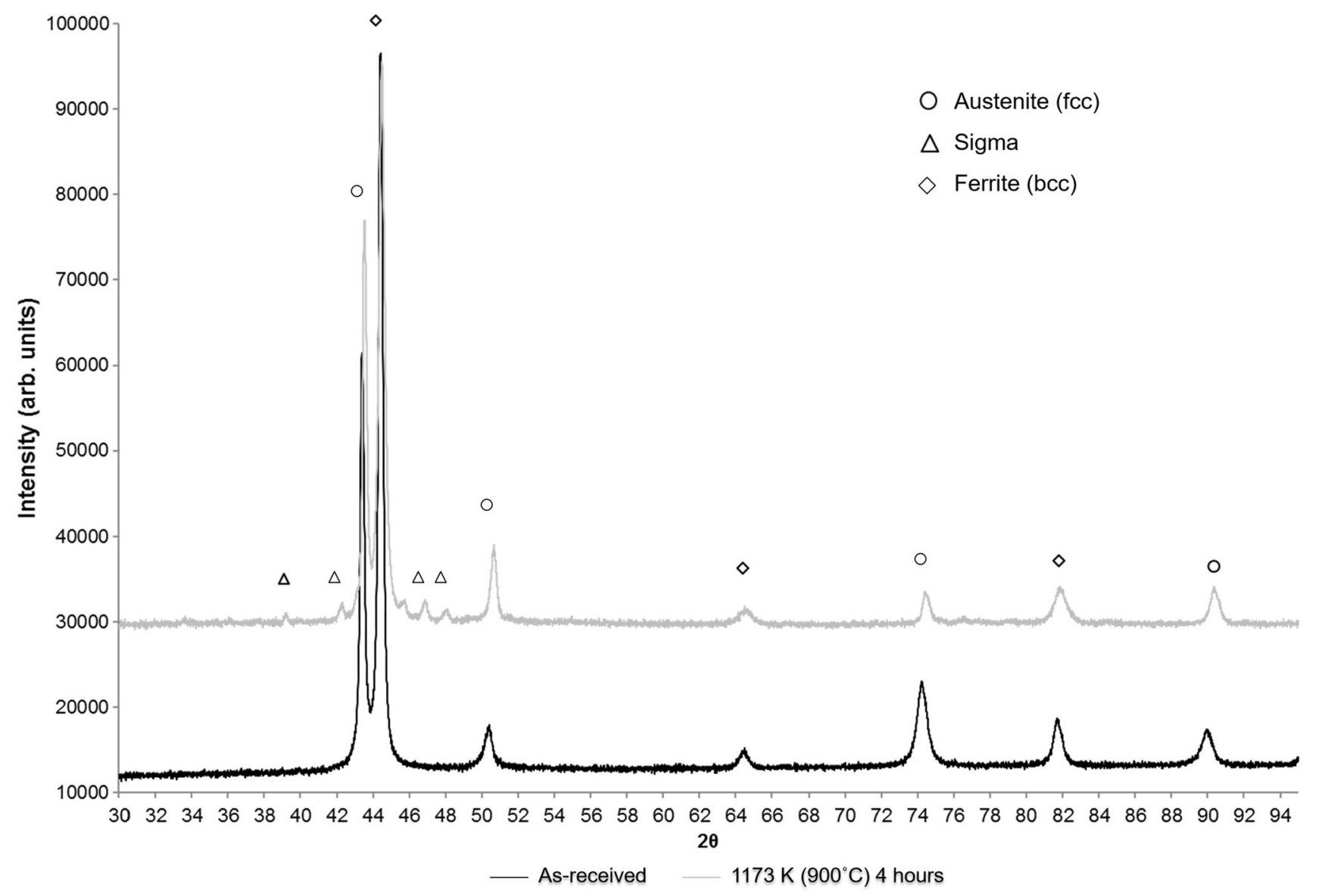

Fig. 5-X-ray diffraction data of the as-received material and the near surface of the samples heat treated at $1173 \mathrm{~K}\left(900{ }^{\circ} \mathrm{C}\right)$ for $240 \mathrm{~min}$.

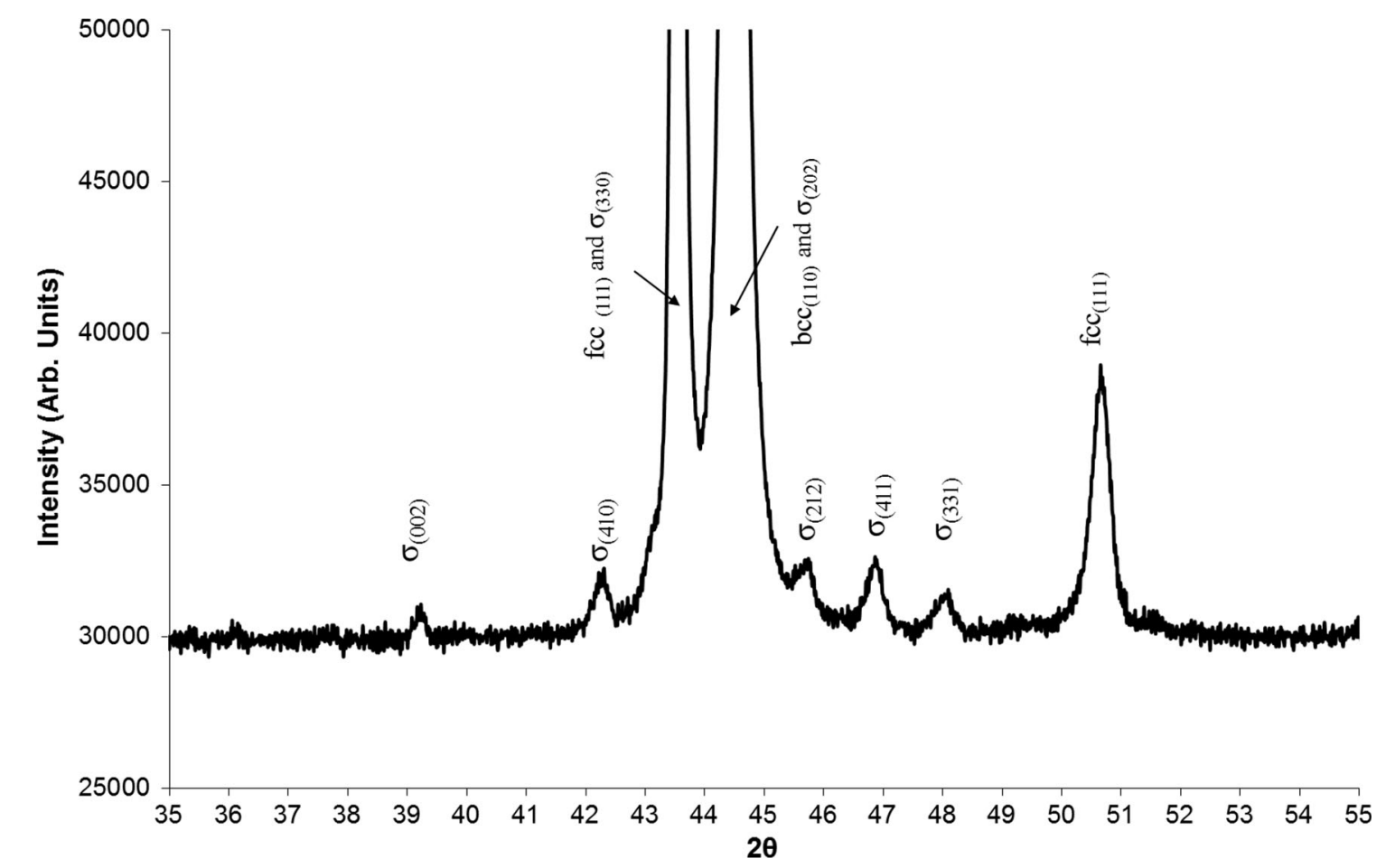

Fig. 6-X-ray diffraction data extract of the data shown in Fig. 4 of the samples heat treated for 240 min at $1173 \mathrm{~K}\left(900{ }^{\circ} \mathrm{C}\right)$ showing the positions of the fcc, bcc, and sigma peaks. 


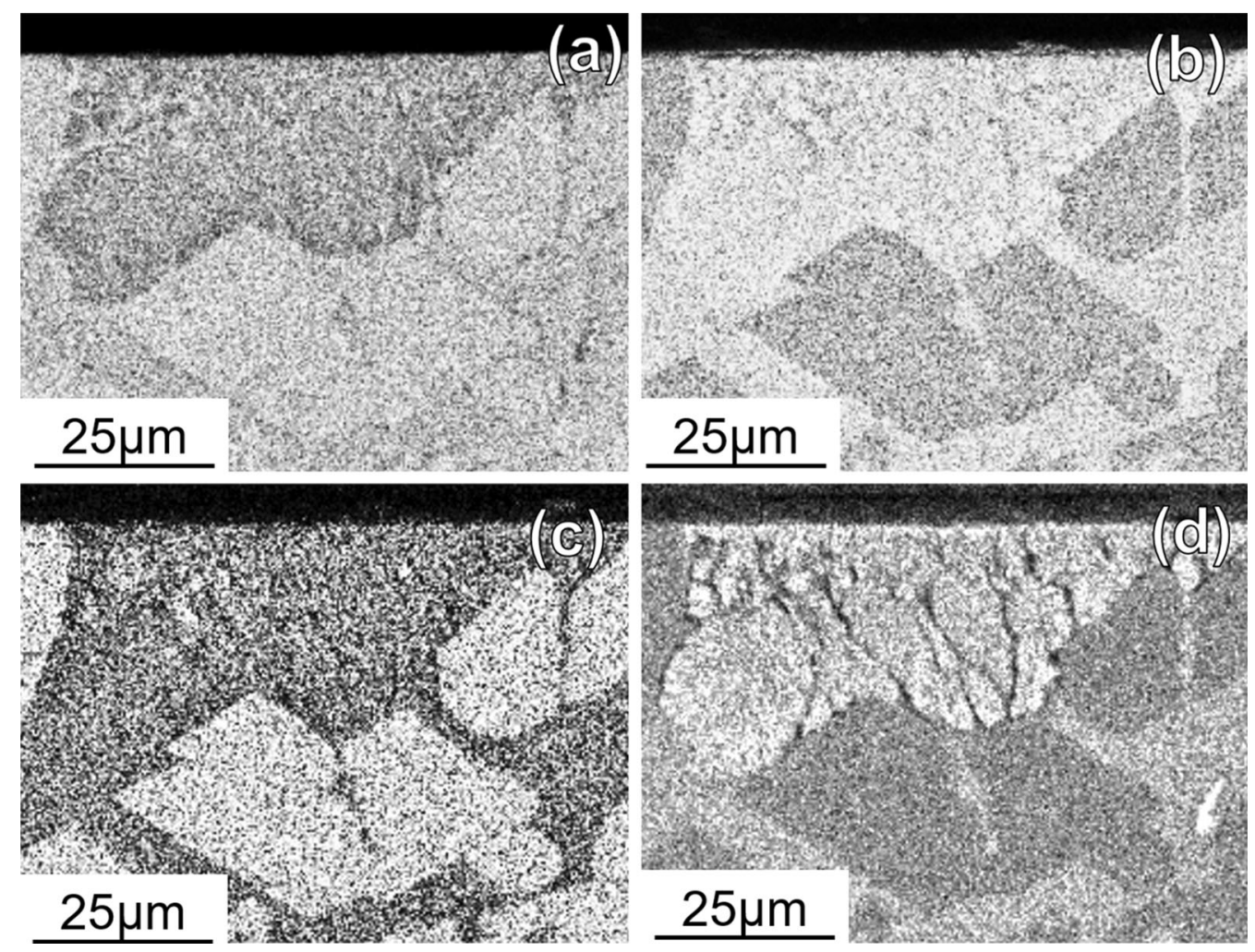

Fig. 7-EDS of the area shown in Fig. 2(b), ground surface finish heat treated at 800 deg for 120 min for $(a)$ iron, $(b)$ chromium, $(c)$ nickel, and (d) molybdenum.

has 4.9 pct. A similar pattern of difference is always seen in the measurements further into the material with the ground surface showing a greater percentage of sigma at each depth band studied. The results from the analysis of the samples heat treated to $1173 \mathrm{~K}\left(900^{\circ} \mathrm{C}\right)$ are shown in Figure 9(b). Again, observations can be made that there is greater sigma at the ground surface but, at this temperature, the percentage of sigma is considerably lower than at $1073 \mathrm{~K}\left(800^{\circ} \mathrm{C}\right)$, and the rate of change with exposure time is much less pronounced.

Figure 10 shows a phase equilibrium plot, produced using Thermocalc (with the TCFE: Steels/Fe-Alloys Database Version 7.0), of the major phases for the composition of the alloy used in this work. At $1073 \mathrm{~K}$ $\left(800{ }^{\circ} \mathrm{C}\right)$, the equilibrium calculations predict that the material will be primarily austenite with $\sim 25 \mathrm{wt}$ pct sigma phase with no other significant phases predicted at this temperature. $1173 \mathrm{~K}\left(900{ }^{\circ} \mathrm{C}\right)$ represents the temperature at which the maximum fraction of austenite is predicted at a mass percentage of between 80 and 85 pct. Above this temperature, the fraction of austenite and sigma is predicted to decrease as the ferrite fraction increases. In agreement with this, samples heat treated in this study at $1273 \mathrm{~K}\left(1000^{\circ} \mathrm{C}\right)$ for up to 180 minutes showed no sigma phase present either at the prepared surfaces or within the bulk. The equilibrium calculations in Figure 10 confirm that this is what would be expected as no sigma is predicted to form above $1223 \mathrm{~K}\left(950{ }^{\circ} \mathrm{C}\right)$.

\section{DISCUSSION}

It is well known that sigma forms in duplex stainless steels at these temperatures, which has limited their use for higher temperatures applications due to its adverse effect on the mechanical properties of the alloy. ${ }^{[14,15]}$ The surface precipitation of sigma has not been previously reported with studies focussing instead on bulk sigma formation. For this reason, the effect of surface finish which has been observed in this study has not been previously noted. This surface effect clearly needs to be considered for use in service as the precipitation of sigma phase may be detrimental to the mechanical properties of the steel, ${ }^{[14,15]}$ and the surface is likely to be the point of failure initiation.

In the present study, it has been shown that sigma phase will form at the surface of 2205 duplex stainless steel after as little as 30 minutes for a ground surface and 60 minutes for a polished surface at both $1073 \mathrm{~K}$ $\left(800{ }^{\circ} \mathrm{C}\right)$ and $1173 \mathrm{~K}\left(900{ }^{\circ} \mathrm{C}\right)$ (Figure 9). After 60 minutes at $1073 \mathrm{~K}\left(800^{\circ} \mathrm{C}\right)$, the ferrite grains at the surface of both a polished and a ground sample have started to transform to sigma phase as shown in Figure 3. As the time increases, the initial sigma phase grows into the material until it impinges on an austenite grain. The structure of the sigma phases at $1073 \mathrm{~K}$ $\left(800{ }^{\circ} \mathrm{C}\right)$ shows a coral-like cellular structure seen in previous studies, ${ }^{[3,4,16]}$ although the morphology is different at $1173 \mathrm{~K}\left(900^{\circ} \mathrm{C}\right)$, Figures 3 and 4. Similar 


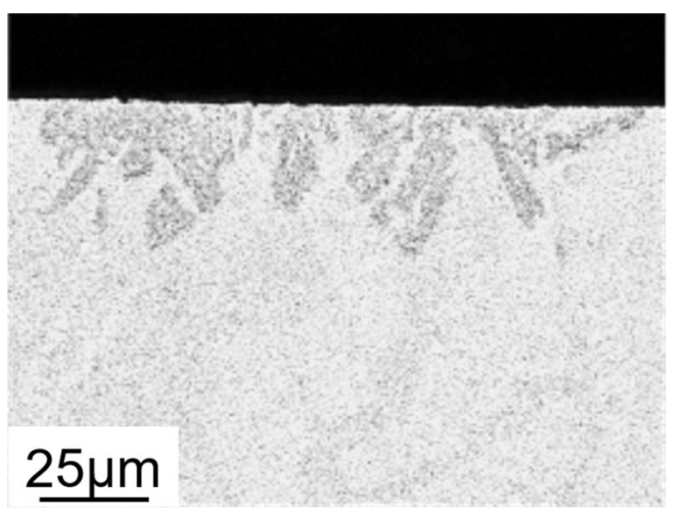

(a)

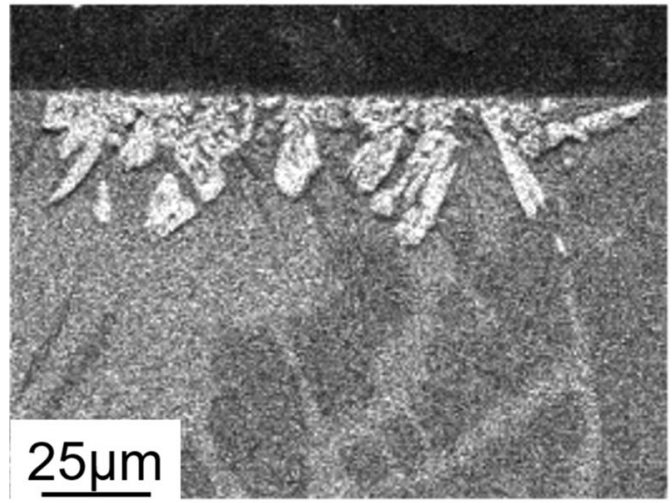

(c)

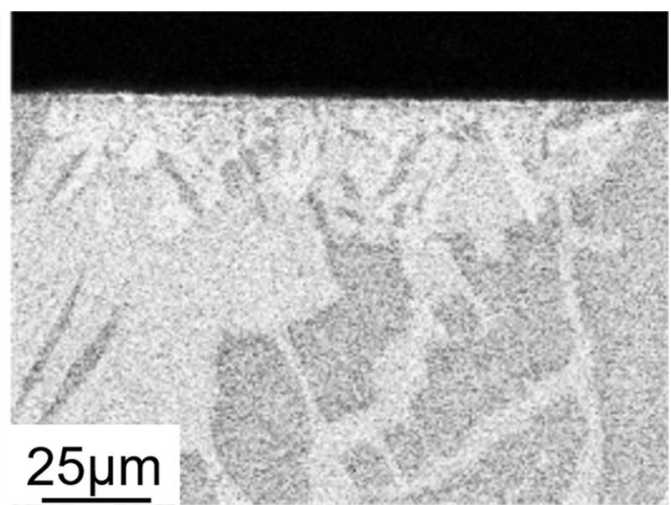

(b)

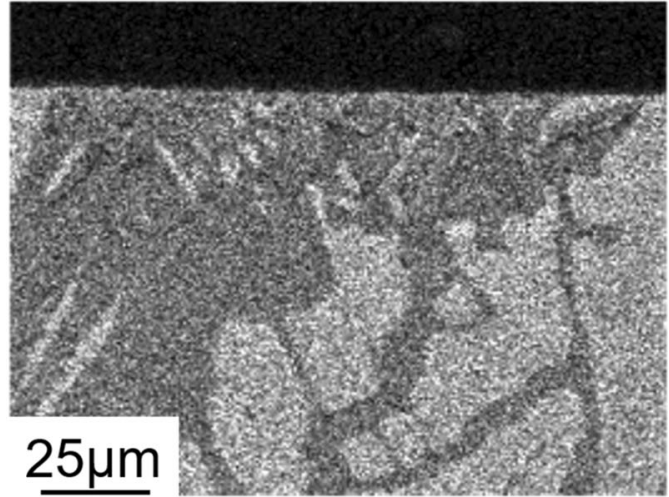

(d)

Fig. 8-EDS of the area shown in Fig. 3(b), ground surface finish heat treated at 900 deg for 120 min for (a) iron, (b) chromium, (c) nickel, and (d) molybdenum.

differences in sigma phase morphology were also noted by Cho and Lee, ${ }^{[17]}$ although this was due to the solution treatment temperature and not the temperature at which the sigma formed. The EDS data for the structure after heating at the temperatures studied here seems to indicate the formation of secondary austenite within the sigma phase region at the surface, Figures 7 and 8 , as the nickel is ejected from the sigma phase. ${ }^{[15,16]}$

The quantification of the sigma phase formation shows that there is a clear increase in both the nucleation and growth rate on the ground surface finish, compared to that on the polished surface, as shown in Figure 9. The surface finish is known to affect the oxidation characteristics of these materials with the oxide growth rate being different on the austenite and ferrite phases due their slight differences in chemistry and crystal structure. ${ }^{[9,10]}$

The differences in sigma phase precipitation can be explained by considering the local cold work produced by the grinding process. The effect of cold work from other operations, such as rolling, on the precipitation of sigma phase in duplex stainless steels has been previously reported $^{[17]}$ and has shown that the bulk area percentage of sigma phase within S32205 duplex stainless steel after heating to $1073 \mathrm{~K}\left(800^{\circ} \mathrm{C}\right)$ increased from $<10$ to $>40$ pet at 0 and 50 pet cold work reduction in thickness respectively. This work built on a study by
Abe et al. ${ }^{[18]}$ in which sigma phase was found to be enhanced after 30 pct cold working of an austenitic alloy. In both cases, the recrystallization of the alloy is of crucial importance, with sigma phase forming at either the austenite/ferrite phase boundary, or at the recrystallization interface as it progresses through the material. It is suggested that the high concentration of dislocations at the recrystallization interface causes an increased rate of diffusion of the sigma-forming elements and/or a greater number of nucleation sites, which supports the results shown here. The penetration depth of the surface precipitated sigma phase increases with time at temperature and extends up to the maximum depth of $120 \mu \mathrm{m}$ measured here. It is known that some surface deformation processes such as shot blasting, for example, can generate damage depths of this order, ${ }^{[19]}$ with $100 \mu \mathrm{m}$ of damage measured for the greatest shot intensity studied. Although similar studies to measure the deformation depth and severity due to the manual grinding and polishing operations used here is rare, it has been suggested that the deformation depth is likely to be in the order of $6 \mu \mathrm{m}$ for a 240 grit prepared sample ${ }^{[20]}$ and could be substantially more for a sample prepared using a greater size of abrasive particle, ${ }^{[20,21]}$ as is common during industrial practice. Therefore, the effect of this grinding-induced cold working is not insignificant. In this work, no evidence has been found 


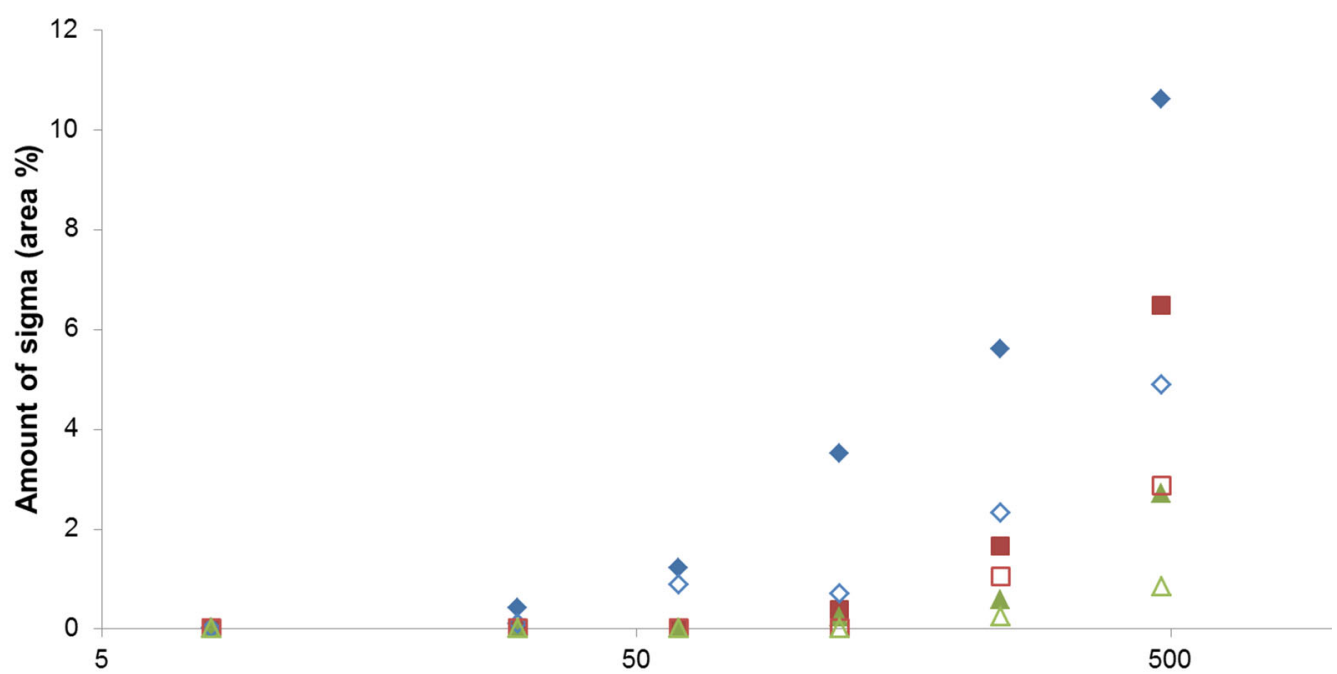

(a)

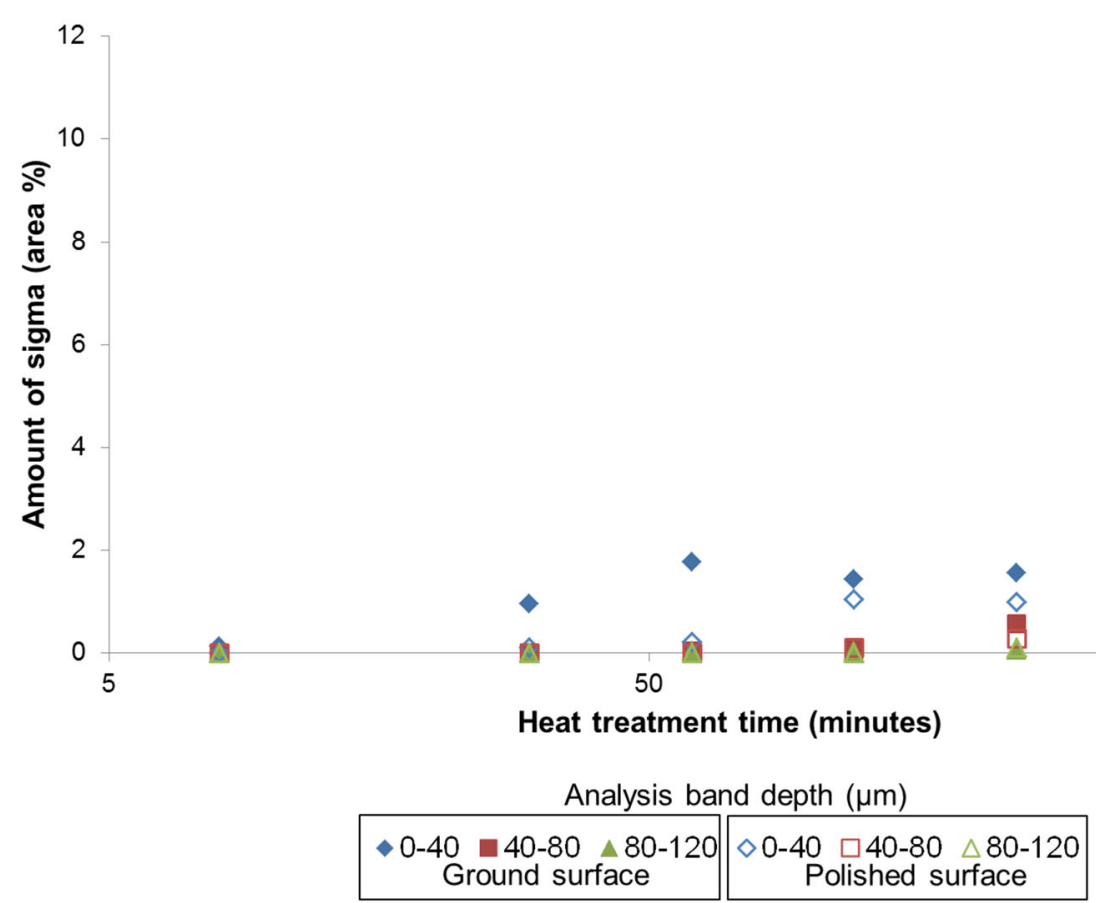

(b)

Fig. 9- Quantification of the area fraction of sigma on the ground and polished samples with increasing time at temperature (a) at $1073 \mathrm{~K}$ $\left(800{ }^{\circ} \mathrm{C}\right)$ and $(b) 1173 \mathrm{~K}\left(900^{\circ} \mathrm{C}\right)$. Solid shapes show the data for the ground surfaces and the outline shapes the polished.

to suggest that the surface formed sigma is formed preferentially at the austenite/ferrite phase boundary but it can be said that it does form only within the ferrite regions of the duplex structure. Having said this, based on the morphological observations from Figures 3 and 4 , it is clear that different formation processes are taking place depending on the temperature experienced. At lower temperatures, a eutectoid reaction takes place which gives rise to the coral-like structure observed ${ }^{[3]} \mathrm{At}$ the higher temperature, in many observations, a more block like structure is observed. This may be caused by the simultaneous nucleation and growth of new austenite grains at the surface (Figure 4).
The structure of the fine grains near to the polished surface of the $1173 \mathrm{~K}\left(900^{\circ} \mathrm{C}\right)$ heat-treated samples, Figures 4(c) and (d), appears to be austenite, although not all of this structure seems to be associated with the sigma phase. The temperature of $1173 \mathrm{~K}\left(900{ }^{\circ} \mathrm{C}\right)$, for this composition, is a critical temperature according to the calculated phase diagram in Figure 10 as it is predicted to be the temperature where there is maximum austenite with no ferrite predicted in the structure. In order to elucidate the effect of this phase change on the formation rate or morphology of the sigma phase within these materials, more work is required. 


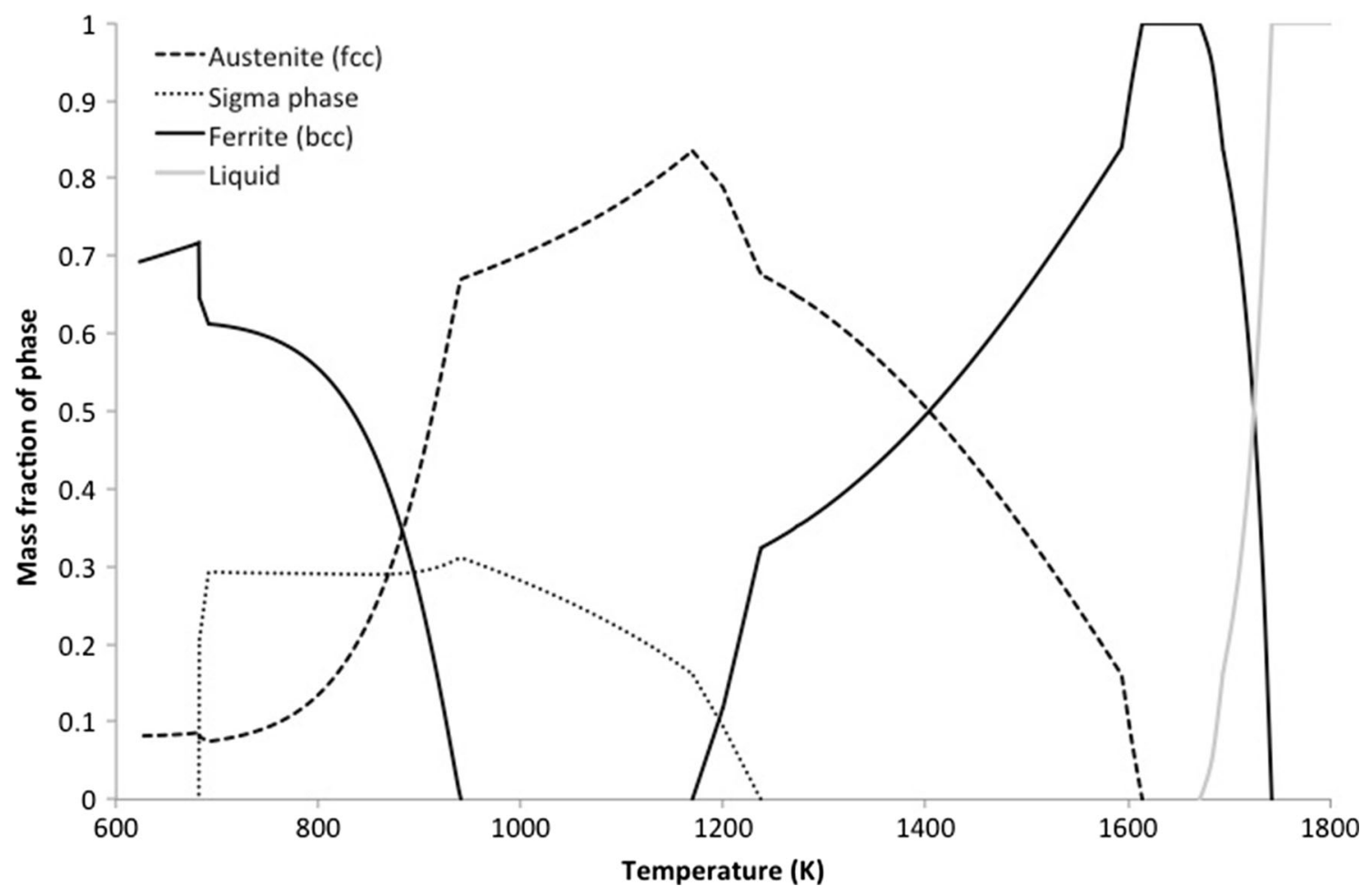

Fig. 10-Equilibrium phase plot of mass fraction of phases at the temperature for 2205 duplex stainless steel calculated using Thermocalc.

\section{CONCLUSIONS}

The precipitation of sigma phase has been investigated at $1073 \mathrm{~K}\left(800{ }^{\circ} \mathrm{C}\right), 1173 \mathrm{~K}\left(900^{\circ} \mathrm{C}\right)$, and $1273 \mathrm{~K}$ $\left(1000{ }^{\circ} \mathrm{C}\right)$ in 2205 duplex stainless steel. Two of the surfaces of the samples were prepared to different surface finishes, ground (240 grit) and polished (6 $\mu \mathrm{m}$ diamond polish), and the surface precipitation of sigma phase quantified. At $1073 \mathrm{~K}\left(800{ }^{\circ} \mathrm{C}\right)$, the sigma phase on the ground surface nucleated and penetrated into the material at a faster rate than on the polished surface. Clear differences were seen to a depth of $120 \mu \mathrm{m}$ from the surface, with approximately double the fraction of sigma phase seen on the ground surface compared to the polished surface at all depths of analysis and thermal exposure times. At $1173 \mathrm{~K}\left(900{ }^{\circ} \mathrm{C}\right)$, the effect of surface finish on the surface precipitation of sigma phase is less evident, possibly due to the bcc to fcc phase transformation at this temperature as predicted by thermodynamic modeling.

The increase in the precipitation and growth rate of sigma at prepared surfaces is discussed with reference to the surface damage associated with the different surface preparation processes. As it is shown that the sigma phase formation is strongly linked to the surface preparation of 2205 duplex stainless steel, these findings have implications for situations where sigma phase at the surface of a component could have an adverse effect on the surface nucleation of defects which could lead to a decrease in fatigue life or fracture toughness of a component.

\section{ACKNOWLEDGMENTS}

The authors would like to thank Dr M. Karunaratne of Loughborough University for performing the thermodynamic calculations and the Loughborough Materials Characterisation Centre for provision of analytical equipment.

\section{OPEN ACCESS}

This article is distributed under the terms of the Creative Commons Attribution 4.0 International License (http://creativecommons.org/licenses/by/4.0/), which permits unrestricted use, distribution, and reproduction in any medium, provided you give appropriate credit to the original author(s) and the source, provide a link to the Creative Commons license, and indicate if changes were made.

\section{REFERENCES}

1. J.-O. Nilsson: Mater. Sci. Technol., 1992, vol. 8, pp. 685-700.

2. G. Fargas, M. Anglada, and A. Mateo: J. Mater. Process. Technol., 2009, vol. 209, pp. 1770-82.

3. D.M.E. Villanueva, F.C.P. Junior, R.L. Plaut, and A.F. Padilha: Mater. Sci. Technol., 2006, vol. 22, pp. 1098-1104.

4. Y. Maehara, Y. Ohmori, and T. Kunitake: Met. Technol., 1983, vol. 10, pp. 296-303.

5. K.W. Chan and S.C. Tjong: Materials, 2014, vol. 7, pp. 5268-304.

6. R. Badji, M. Bouabdallah, B. Bacroix, C. Kahloun, B. Belkessa, and H. Maza: Mater. Charact., 2008, vol. 59, pp. 447-53. 
7. C.-C. Hsieh and W Wu: ISRN Metall., 2012, vol. 2012, pp. 1-16.

8. R. Magnabosco: Mater. Res., 2009, vol. 12, pp. 321-37.

9. M.A.E. Jepson and R.L. Higginson: Corros. Sci., 2012, vol. 59, pp. $263-9$.

10. M.A.E. Jepson and R.L. Higginson: Corros. Sci., 2009, vol. 51, pp. $588-94$

11. J.A. Jimenez, M. Carsi, O.A. Ruano, and F. Penalba: J. Mater. Sci., 2000, vol. 35, pp. 907-15.

12. J.L. Garin and R.L. Mannheim: Powder Diffr., 2012, vol. 27, pp. 131-35.

13. J.W. Elmer, T.A. Palmer, and E.D. Specht: Metall. Mater. Trans. $A, 2007$, vol. 38 , pp. $464-75$.

14. T. Borvik, H. Lange, L.A. Marken, M. Langseth, O.S. Hopperstad, M. Aursand, and G. Rorvig: Mater. Sci. Eng. A, 2010, vol. 527, pp. $6945-55$.
15. M. Pohl, O. Storz, and T. Glogowski: Mater. Charact., 2007, vol. 58, pp. 65-71.

16. A. Kashiwar, N. Phani Vennela, S.L. Kamath, and R.K. Khatirkar: Mater. Charact., 2015, vol. 74, pp. 55-63.

17. H.S. Cho and K. Lee: Mater. Charact., 2013, vol. 75, pp. $29-34$

18. F. Abe, H. Araki, and T. Noda: Mater. Sci. Technol., 1988, vol. 4, pp. 885-93.

19. D.J. Child, G.D. West, and R.C. Thomson: Acta Mater., 2011, vol. 59 , pp. $4825-34$.

20. P.T. Pinard, P. Hovington, M. Lagace, G.F. Vander Voort, and R. Gauvin: Microsc. Microanal., 2010, vol. 16 (Suppl 2), pp. 700-701.

21. W. Taylor and J.S. White: J. Mater. Sci., 1974, vol. 9, pp. $569-75$. 